\title{
Discursos Contemporâneos sobre as Transexualidades: Poder, Verdade e
}

\section{Subjetivação}

\author{
Mariana Pombo* \\ Universidade Federal Rural do Rio de Janeiro - UFRRJ, Seropédica, RJ, Brasil \\ ORCID: https://orcid.org/0000-0002-6896-6691
}

\section{RESUMO}

Baseado na concepção foucaultiana das relações entre saber e poder, este artigo pretende apresentar alguns discursos contemporâneos sobre as transexualidades e problematizar seus efeitos sobre a escuta clínica de pacientes trans. Primeiramente, analisarei como alguns discursos sobre as transexualidades, produzidos nos campos da psicanálise e da medicina, generalizam e mesmo patologizam as experiências trans, se apresentando como detentores de uma verdade única sobre elas. Argumentarei que essas generalizações têm efeitos sobre os pacientes, que se pensarão a partir de certas categorias produzidas pelos saberes contemporâneos, e sobre os próprios analistas, que os receberão na clínica a partir das teorias que julgam verdadeiras. Em seguida, recorrerei, então, a alguns autores da teoria queer e da psicanálise, para defender a possibilidade de novos olhares sobre os sujeitos trans e também de novas direções para a sua escuta clínica na atualidade, uma escuta que tenha como norte a singularidade de cada paciente e de seu desejo.

Palavras-chave: transexualidades, discurso, poder, teoria queer, psicanálise.

\section{Contemporary Discourses on Transexualities: Power, Truth and}

\section{Subjectivation}

\begin{abstract}
Based on Foucault's conception of the relations between knowledge and power, this article intends to present some contemporary discourses on transexualities and to problematize their effects on psychoanalytic clinic of transexual patients. First, I will analyze how some generalizing and/or pathologizing discourses on transexualities, produced in the fields of psychoanalysis and medicine, function as laws of truth and affect the way transexuals understand themselves and are understood and treated. Then I will use some authors from queer theory and psychoanalysis to defend the possibility of new regards on transexualities and also new directions for clinical listening nowadays.
\end{abstract}

Keywords: transexualities, discourse, power, queer theory, psychoanalysis. 


\section{Discursos Contemporáneos sobre las Transexualidades: Poder, Verdad y}

\section{Subjetivación}

\section{RESUMEN}

Basado en la concepción foucaultiana de las relaciones entre saber y poder, este artículo pretende presentar algunos discursos contemporáneos sobre las transexualidades y problematizar sus efectos sobre la escucha clínica de pacientes transexuales. Primero, analizaré cómo algunos discursos sobre las transexualidades, producidos en los campos del psicoanálisis y de la medicina, generalizan e incluso patologizan las experiencias trans, presentándose como poseedores de una verdad única sobre ellas. Argumentaré que estas generalizaciones tienen efectos en los pacientes, que se pensarán a partir de ciertas categorías producidas por los saberes contemporáneos, y en los propios analistas, que los recibirán en la clínica a partir de las teorías que consideran verdaderas. A continuación, recurriré entonces a algunos autores de la teoría queer y del psicoanálisis, para defender la posibilidad de nuevas perspectivas sobre los sujetos trans y también de nuevas direcciones para su escucha clínica en la actualidad, una escucha que tenga como guía la singularidad de cada paciente y de su deseo.

Palabras clave: transexualidades, discurso, poder, teoría queer, psicoanálisis.

Em junho de 2019, completou-se um ano que a transexualidade foi retirada da categoria de doenças mentais da CID (Classificação Estatística Internacional de Doenças e Problemas Relacionados com a Saúde), organizada pela OMS (Organização Mundial de Saúde): ela saiu do grupo dos "transtornos de identidade de gênero", que pertencia ao capítulo dos "transtornos de personalidade e comportamento", e passou a ser classificada como “incongruência de gênero", dentro do capítulo das "condições relacionadas à saúde sexual”. Trata-se, sem dúvida, de um passo muito importante dado na direção da despatologização das transexualidades e, consequentemente, espera-se, da sua desestigmatização e maior acolhimento e respeito nos diversos espaços da sociedade.

Paralelamente a essa conquista, multiplicam-se os discursos sobre as transexualidades, na forma seja de textos acadêmicos, seja de produções culturais, como filmes de ficção, documentários e séries televisivas. No que diz respeito aos saberes clínicos, esse fenômeno também se dá. No campo da psicanálise, por exemplo, muitos autores têm se debruçado sobre a clínica de pacientes transexuais e tentado produzir teorias que direcionem o seu tratamento.

Nesse contexto, a escrita deste artigo surge, em primeiro lugar, do incômodo em relação a alguns discursos veiculados na contemporaneidade, devido ao seu caráter generalizante - e muitas vezes também patologizante - das experiências transexuais, ou seja, 
que colocam na mesma categoria ou estrutura indivíduos com histórias, questionamentos e vivências tão diferentes. Em segundo lugar, da aposta justamente em novos olhares possíveis para as transexualidades, que contemplem variadas posições subjetivas e, assim, uma clínica que pense o caso a caso e que possibilite aos pacientes a criação de percursos subjetivos absolutamente singulares.

Parte-se aqui da perspectiva foucaultiana sobre as relações entre saber (discurso) e poder (Foucault, 1969, 1979/2007, 1983), que estão diretamente implicados em duas dimensões: de um lado, relações de poder geram objetos para o saber e, de outro, o saber reconduz e reforça efeitos de poder. Desse modo, trata-se de atentar para o fato de que cada cultura oferece ao saber novos objetos merecedores de atenção e cuidado, objetos a serem conhecidos e estudados. E o novo saber produzido funciona como leis de verdade que configuram formas de normalidade e desvio, normas a partir das quais os indivíduos se pensam e são tratados.

Em "Microfísica do poder", Foucault (1979/2007) afirma que cada sociedade tem sua "política geral de verdade" (p. 12), que inclui os discursos que ela acolhe e faz funcionar como verdadeiros, as instâncias que permitem distinguir os enunciados verdadeiros dos falsos, o estatuto daqueles que têm a função de dizer o que funciona como verdadeiro.

Desse modo, a primeira parte do artigo se ocupará justamente de criticar discursos que têm a pretensão de dizer a "verdade" única sobre os sujeitos transexuais, produzindo saberes unitários, e problematizar seus efeitos sobre a clínica. Em seguida, veremos como a teoria queer e também a psicanálise, no diálogo com ela, nos oferecem a possibilidade de delinear novos discursos sobre as transexualidades na atualidade e sobre a própria clínica.

\section{Discursos generalizantes sobre as transexualidades}

\section{Saberes psicanalíticos}

No seminário 18, Lacan (1971/2009) comenta que o seu conceito de foraclusão ${ }^{1}$ poderia ser útil para a compreensão dos pacientes transexuais descritos por Robert Stoller (1968) em "Sex and Gender", primeira obra psicanalítica a abordar o tema das transexualidades e a trazer para a psicanálise a noção de identidade de gênero. Nesse livro e também em “A experiência transexual”, de 1975 (tradução de 1982), Stoller utiliza o termo transexualismo e se refere a ele como desordem, patologia, ilusão, mas não defende que se 
trate de psicose. É Lacan (1971/2009) que aponta a face psicótica dos casos apresentados no primeiro livro.

Embora Lacan não tenha defendido aí que toda pessoa transexual seja psicótica, pois estava comentando casos de uma obra específica, nas décadas seguintes alguns psicanalistas lacanianos, como Czermak (1982), Millot (1992), Melman (1996), Frignet (2002) e Castel (2003), sustentaram o entendimento das transexualidades como psicose, associando-as à recusa da lei simbólica. Millot (1992), por exemplo, cujas ideias, segundo Porchat (2018), continuam sendo repetidas em artigos de analistas nos anos 2015, 2016 e 2017, intitula seu livro de "Hors sexe" (fora do sexo), traduzido para o português como "Extrasexo", porque entende o sujeito transexual como psicótico, situado fora da diferença sexual.

Alguns desses discursos associam também as experiências transexuais à cultura contemporânea, como é o caso de Frignet (2002), em "O transexualismo". Esse autor entende que o "fenômeno transexual" (p. 16) - o aumento do número de transexuais na atualidade seria uma resposta à recusa social da diferença sexual e ao declínio da imago paterna. Ou seja, as transexualidades e suas demandas de mudanças corporais e de sexo são interpretadas por ele como consequência de transformações no campo da sexualidade e da família, entendidas como negativas.

A modificação das relações entre os sexos e da dinâmica familiar que vem ocorrendo recentemente em nossa cultura, com a colocação em questão da dominação masculina, o patriarcado e a norma heterossexual pelos movimentos feminista e de minorias sexuais, é vista nesse discurso por uma ótica declinológica, como se ameaçasse a cultura, em vez de reconhecida como avanço. A visão declinológica do contemporâneo, por sua vez, decorre de uma compreensão estruturalista e ahistórica da diferença sexual ${ }^{2}$ : a divisão binária dos sexos estaria no fundamento da "ordem simbólica” indispensável à subjetivação, ordem que estaria sendo atacada justamente por essas mudanças recentes nas sexualidades, gêneros e famílias.

Por um lado, Frignet (2002) segue a ideia dos autores já citados de que o transexual seria psicótico, devido à foraclusão do Nome-do-Pai. Como Millot (1992), afirma que ele está "fora do sexo", devido à rejeição da diferença sexual. Sem a diferença sexual inscrita no inconsciente e sem identidade sexual estabelecida, portanto, o transexual apresentaria a convicção delirante de pertencer ao sexo oposto àquele designado ao nascer e, ao solicitar a mudança de sexo, estaria demandando uma inscrição simbólica ainda não realizada.

Por outro lado, Frignet (2002) distingue um segundo tipo de "transexualismo", a que chama de transexualista. Ainda que nos dois casos houvesse, de acordo com o autor, uma falha na relação com o falo enquanto ordenador da sexualidade, o transexualista seria 
perverso, e não psicótico. Ele teria a identidade sexual estabelecida, saberia a que sexo pertence, mas desejaria ser reconhecido como pertencendo ao sexo oposto.

A recusa da diferença sexual do transexualista seria perversa ou, ainda, seria uma resposta do sujeito à convocação social a essa recusa: a ciência, a medicina, a mídia, a justiça, ao repetir que a escolha do sexo é um direito individual, contribuiriam para o apagamento da diferença sexual e inflariam o "fenômeno transexual". Inflariam também a demanda pela mudança de sexo, mudança entendida por Frignet como impossível, já que para ele a diferença sexual impõe limites intransponíveis:

É com esse impossível que está confrontado o transexualismo: impossível para todo aquele que quiser mudar de sexo, sejam quais forem as modificações de sua aparência física, e até aquelas que a lei real conceder por decisão de justiça. Um sujeito humano não pode escapar a esse real que o fez nascer homem ou mulher. (Frignet, 2002, pp. 93-94)

A crítica que faço aqui a esse tipo de discurso é que, ao partir de uma norma (heterossexual, binária) prevista para a configuração das sexualidades e das identificações, produz compreensões patologizantes das transexualidades, já que elas se afastariam dessa norma. Por isso, as transexualidades acabam sendo entendidas como um "desvio", "desvio" que, inclusive, segundo Frignet (2002), seria reforçado ou mesmo induzido pela cultura em que vivemos.

Judith Butler, em entrevista concedida a Porchat (2010), defende que é “invariavelmente patologizante" (p. 163) colocar a transexualidade na categoria de psicose, posicionando-se de modo contrário a psicanalistas lacanianos que entendem que falar de estrutura psicótica nesse caso não seria patologizante. Para ela, esse tipo de teoria é patologizante porque se apoia em um modelo de desenvolvimento de diferenciação ou identificação de gênero (na direção da "condição de menina" ou da "condição de menino"), modelo que o transexual não seguiria e, por isso, seria dito psicótico.

Não podemos estabelecer a priori que transexuais padecem de uma patologia ou são necessariamente, por uma questão de estrutura, psicóticos. A clínica psicanalítica nos ensina que, antes de tudo, devemos escutar e basicamente tentar acolher as diversas manifestações das subjetividades. Sabemos que estamos num território movediço, bastante complexo e que não devemos ceder de imediato ao apelo do imperativo 
tecnológico e científico que pretende capturar e modelar os corpos. Porém, mais do que nunca, não podemos - em nome de uma antiga forma de organização social, que alguns preferem chamar de Lei - impor de forma violenta um diagnóstico psiquiátrico ou realizar uma interpretação psicanalítica, apenas para manter o nosso horizonte simbólico intocável. (Arán, 2006, pp. 59)

Alguns psicanalistas contemporâneos, como Márcia Arán, citada acima, também criticam a tradução da transexualidade em um modo de funcionamento específico ou em uma estrutura, entendendo que as posições subjetivas transexuais são múltiplas. Indo na mesma linha de raciocínio, Porchat (2018) lembra que o termo gênero já entrou no vocabulário psicanalítico, por meio de Stoller, associado à patologia e que sua obra marca o pensamento dos psicanalistas sobre pessoas trans. A psicanalista também critica a busca incessante por etiologias e a redução das experiências trans a leituras que pressupõem modelos históricotradicionais de homem, mulher e desejo sexual heterossexual.

Além de psicose e perversão, a transexualidade também é entendida por outros autores da psicanálise como uma patologia narcísica, próxima aos estados-limites (Chiland, 2008), ou, mais recentemente, como histeria (Jorge \& Travassos, 2017).

Para Colette Chiland (2008), o "transexualismo" (termo que ela usa e que é título de seu livro) se situaria na encruzilhada de todas as patologias. A autora discorda de que se trate de psicose e opta por aproximá-lo dos estados-limites: acredita o sujeito transexual, marcado por uma insegurança profunda, só consegue construir seu eu e o sentimento de existir a partir de uma identidade sexual contrária a que lhe foi atribuída.

Enquanto Frignet (2002) entende que os transexuais recusam a diferença sexual, Chiland (2008) pensa que eles a afirmam, mas querem ser do outro sexo e toleram com dificuldade a mescla de masculino e feminino em si. Porém, assim como ele, a autora sustenta a diferença sexual como estrutura ahistórica e também considera da ordem do impossível e da loucura a mudança de sexo:

É completamente irracional negar a existência da "diferença sexual". Todas as características psicológicas podem estar presentes num ou no outro sexo, como acabamos de ver. Mas derivam da biologia, do corpo, algumas características que não se podem apagar. Assumir a identidade de homem ou de mulher é aceitar as características do macho ou da fêmea. A diferença culmina no ato sexual e na 
procriação, mas está presente na vivência do corpo próprio e no ciclo psicossexual. (Chiland, 2008, pp. 100)

Já Jorge e Travassos (2017) propõem que a transexualidade seria a forma da figura clínica da histeria aparecer na contemporaneidade, atualizando a interrogação, própria à estrutura histérica, sobre o enigma da diferença sexual (sou homem ou mulher?). A certeza transexual de pertencer ao sexo oposto ao designado no nascimento seria uma tentativa de responder a esse enigma.

Os autores entendem que estamos diante de uma epidemia histérica, produzida pela medicina ao oferecer respostas imediatas, como o processo transexualizador, para conflitos do sujeito com o seu sexo: "o elevado número de casos de transexualidade tem tudo para ser considerado uma nova epidemia de histeria, talvez mesmo uma pandemia de histeria - uma epidemia na era da globalização" (Jorge \& Travassos, 2017, p. 316). O aumento da procura pela destransição também corroboraria essa hipótese, na medida em que revelaria a insatisfação histérica.

Como será discutido no item seguinte, é claro que o aumento do número de pessoas que se reconhecem como transexuais hoje e a participação da medicina e da mídia na construção da "verdadeira transexualidade" e dos "tratamentos" adequados são elementos contemporâneos importantes, que suscitam questionamento e reflexão. O que se configura como problemático, porém, mais uma vez, é o caráter universalizante dos discursos expostos, como se contivessem uma verdade única a respeito das experiências transexuais, que são tão singulares.

Na clínica observamos, por exemplo, que nem toda pessoa que se autoidentifica como transexual tem certeza sobre pertencer ao outro sexo ou recorre necessariamente ao processo transexualizador. Porchat (2018) afirma que há diversas formas de subjetivação e de construção de gênero, que vão na contramão de teorias que tipificam a pessoa transexual em uma posição subjetiva única, e nos alerta para os efeitos de poder da psicanálise quando fala de modo tão determinante sobre o outro.

O psicanalista Thamy Ayouch (2015) também defende que as transexualidades não podem ser apreendidas a partir de categorias psi preexistentes: "Sustento que quando a psicanálise considera a transexualidade como uma categoria que existe ontologicamente, em si, ela se torna antipsicanalítica, produzindo uma resistência a si mesma e ao seu exterior" (Ayouch, 2015, p. 23-24). Para ele, precisamos nos afastar de modelos etiológicos ou 
nosográficos que se pretendam generalizáveis, se quisermos respeitar a hipersingularidade de cada sujeito.

\section{Saberes médicos}

O segundo grupo de discursos contemporâneos sobre as transexualidades, que também se apresenta como generalizante e tem efeitos sobre a clínica merecedores da nossa atenção, está no campo da medicina. Ainda que, como foi dito na introdução deste texto, a transexualidade não seja mais considerada uma doença mental na CID, existem saberes produzidos pela medicina sobre quem são os pacientes transexuais e como se deve cuidar deles, saberes bastante difundidos e presentes em nosso imaginário social.

Bento (2012), em "O que é transexualidade", mostra como os médicos desde a década de 50 do século passado, e com mais intensidade ao longo dos anos 60 e 70, empenharam-se para estabelecer critérios diagnósticos da transexualidade, isto é, indicadores que permitissem verificar o "verdadeiro transexual", diferenciando-o, por exemplo, do homossexual.

Atualmente há três documentos médicos que descrevem as transexualidades: a CID, já citada, o DSM (Manual de Diagnóstico e Estatísticas de Distúrbios Mentais, da Associação de Psiquiatria Americana), e o SOC (State of Care, da Associação Internacional de Disforia de Gênero Harry Benjamin, que publica normas de tratamento para pessoas transexuais no mundo todo). Enquanto os dois primeiros se dedicam a descrever critérios diagnósticos, o terceiro reúne orientações sobre o manejo psiquiátrico, psicológico, médico e cirúrgico dos "transtornos de gênero".

Esses documentos têm em comum a oferta de propostas universais de diagnóstico ou tratamento para transexuais, independentemente tanto de variáveis culturais, sociais e econômicas, como de fatores particulares à história de cada um. A crítica trazida por Bento (2012) é que essa categoria de transexualidade produzida pela medicina e difundida na cultura conduz à ideia de que existe um sujeito transexual universal e homogêneo, como se todos que vivem experiências transexuais compartilhassem o mesmo sofrimento e modos semelhantes de lidar com ele e reduzi-lo. No que tange aos modos de lidar com o sofrimento, a autora expõe também como as normas de tratamento descritas no SOC privilegiam a indicação da cirurgia de transgenitalização em detrimento das psicoterapias, que, de acordo com essas normas, poderiam ser inúteis diante do grande desconforto apresentado pelo transexual em relação ao corpo e aos órgãos genitais. 
Portanto, minha crítica a esses saberes médicos sobre as transexualidades, seguindo os passos de Bento, é que os desconfortos e os conflitos das esferas do corpo e da sexualidade são múltiplos, e sua categorização e tratamento pela medicina são generalizantes e reducionistas. Não se trata de modo algum de ocupar uma posição a priori contrária ao tratamento hormonal ou ao recurso às cirurgias, que são importantes para muitas pessoas trans, mas de desconfiar de diagnósticos e direcionamentos clínicos que se propõem como ahistóricos e universais, válidos em qualquer cultura e para qualquer indivíduo.

Por que considerar esta experiência identitária uma doença? Quem autoriza os psicólogos, psiquiatras, endocrinologistas, e outras especialidades que fazem parte das equipes multidisciplinares, a avaliar a pessoa transexual como "doente"?... O único mapa seguro que guia o olhar do médico e dos membros da equipe são as verdades estabelecidas socialmente para os gêneros. Não existe um só átomo de neutralidade. Estamos diante de um poderoso discurso que tem como finalidade manter os gêneros prisioneiros à diferença sexual. (Bento, 2012, pp. 87, grifos meus)

É interessante observarmos que, se a criação do discurso médico bebe na fonte de uma norma binária de entendimento dos sexos e dos gêneros, ele também reforça de modo contundente esse binarismo, e é esse efeito que deve ser problematizado por nós. Bento (2012) mostra, por exemplo, como o DSM-IV caracteriza o "transtorno da identidade de gênero" na infância a partir da preferência da criança por roupas, atividades ou brincadeiras "tradicionalmente" atribuídas ao gênero oposto. O manual alerta então que merecem atenção e intervenção terapêutica de um lado o menino que brinca de casinha e de Barbie, desenha princesas, demonstra pouco interesse por carrinhos, caminhões ou outros brinquedos "agressivos", e de outro a menina que prefere usar "roupas de menino" e cabelo curto, e gosta de super-heróis como Batman e Super-homem.

Retomando o pensamento de Foucault e as ideias de Bento, sabemos que o discurso médico produz leis de verdade, é poderoso, como diz a socióloga no trecho citado logo acima. Isso significa então que é a partir do que ele diz que é o "verdadeiro transexual" e quais são os modos de lidar com ele que tanto médicos como pacientes darão sentido às experiências trans, do outro ou suas próprias.

"Não há um verdadeiro transexual, mas a psiquiatria e algumas psicanálises o criam e creem" (Porchat, 2018, p. 80). A psicanalista Patrícia Porchat (2014, 2018) também problematiza os efeitos políticos das generalizações, tanto para as pessoas trans como para os 
analistas: enquanto as pessoas trans se veem e são tratadas a partir de políticas públicas baseadas em visões patologizantes, os analistas se tornam reféns dessa mesma patologização das subjetividades.

Porchat (2014) chama a atenção para o fato de que a transexualidade hoje é um termo guarda-chuva, que abriga diferentes formas de transitar entre os gêneros e também diferentes tipos de intervenções e mudanças corporais. A categorização da transexualidade como uma entidade nosológica psiquiátrica no CID e no DSM, e a definição de critérios para sua identificação e tratamento, porém, tem efeitos complexos. Se, por um lado, a transexualidade encontra um lugar na saúde e tem acesso a práticas médicas que podem responder ao seu sofrimento, por outro se delimitam quem são os "verdadeiros transexuais", desqualificando-se as experiências pessoais em relação ao sexo e gênero que não se enquadram nos padrões estabelecidos, que acabam também excluídas dos cuidados oferecidos pelos sistemas de saúde.

A autora também põe em questão a participação da mídia hoje na veiculação do que seria a transexualidade e das possibilidades de intervenção hormonal e cirúrgica, o que acaba contribuindo para o aumento de pessoas, sobretudo crianças e adolescentes, que se identificam ou são identificadas pelos pais como transexuais e buscam ajuda médica para dar início ao processo transexualizador:

Não há como negar os benefícios para as pessoas transexuais que se autorizam a sair do armário, como aconteceu em relação à homossexualidade, mas quero aqui reiterar que, em alguns casos, a rápida autoidentificação como resposta ao desconforto e ao mal-estar é problemática. (Porchat, 2014, pp. 122)

Seguindo o alerta de Porchat, na clínica psicanalítica, devemos estar alertas e nos questionar, portanto, sobre as duas implicações dos efeitos dessas generalizações: sobre os pacientes e sobre nós mesmos. No que diz respeito aos pacientes, é importante investigarmos se, ao se autoidentificarem com a categoria médica de transexualidade, cristalizam a percepção de si em uma identidade, em um conjunto de elementos definidos a priori, e têm dificuldade em entrar em contato com seus conflitos, incômodos e desejos próprios.

Não estou defendendo aqui que seria possível acessarmos uma subjetividade, ou mesmo um inconsciente, livre, aquém ou além dessas normas generalizantes disponíveis em nossa cultura, visto que o sujeito se constitui justamente a partir dessas mesmas normas, do regime de verdade produzido pelo poder de sua época (Foucault, 1969, 1979/2007, 1983). Isto 
é, o sujeito não é o outro do poder, e sim um dos seus primeiros efeitos. Na passagem seguinte de "Microfísica do poder" esse argumento fica evidente: "Afinal, somos julgados, condenados, classificados, obrigados a desempenhar tarefas e destinados a um certo modo de viver ou morrer em função dos discursos verdadeiros que trazem consigo efeitos específicos de poder" (Foucault, 1979/2007, p. 180).

Butler (1997/2017), em “A vida psíquica do poder”, também é clara quanto a isso: tornar-se sujeito significa simultaneamente o devir do sujeito e sua sujeição ao poder, isto é, a internalização das normas. E vai ainda mais longe: há mesmo um desejo do sujeito pela norma, na medida em que essa sujeição é sua condição de possibilidade, de existência social. Porém, ainda de acordo com Butler e Foucault, ao mesmo tempo em que é constituído pelo poder, o sujeito o exerce, reiterando-o, certamente, mas também o dissimulando e invertendo. Isto é, a transformação das normas pode se dar no próprio campo das relações de poder. É interessante também que Butler (1997/2007, 2004) recorra aos conceitos de inconsciente em "A vida psíquica do poder" e de pulsão em "Deshacer el género" quando aborda as possibilidades de resistência e deslocamentos subjetivos no campo das normas. É nesse sentido que entendo a possibilidade de os pacientes transexuais percorrerem em análise um processo singular de questionamento e de elaboração de conflitos, conflitos inclusive produzidos pelo próprio fato da imersão necessária no sistema normativo.

Já no que tange a nós mesmos enquanto analistas, é preciso nos lembrarmos de que as categorias e teorias que julgamos verdadeiras e a partir das quais ouvimos nossos pacientes também configuram normas e têm efeitos subjetivos e clínicos. A própria psicanálise é um campo atravessado por jogos de poder e verdade (Foucault, 1979/2007, 1983) e estamos todos - pacientes, analistas, clínica - imersos no sistema normativo. Mais uma vez, porém, reconhecer essa impossibilidade de escuta fora das normas não significa que toda escuta reforce as normas hegemônicas e excludentes. É importante reforçar que estamos partindo aqui do pressuposto de que nossos referenciais teóricos são normas históricas, passíveis de transformação, e não leis universais, imutáveis. O que defendo aqui, portanto, é que ressignificações, transgressões normativas possam se dar no setting analítico quando entendemos as subjetividades e as sexualidades, e as teorias e os discursos sobre elas como historicamente produzidas. 


\section{Discursos queer sobre as transexualidades}

A teoria queer, conjunto de enunciados produzidos a partir dos anos 1980 sob importante influência de Foucault, nos aponta caminhos interessantes para a produção de novos discursos sobre as transexualidades, por trabalhar no sentido da desconstrução e desnaturalização do sistema binário de sexo e de gênero, e da valorização das instabilidades e rupturas com as normas.

Em "Problemas de gênero: feminismo e subversão da identidade", Butler (1990/2013), defende que a categoria sexo, tida em nosso imaginário social como natural e ahistórica, é uma construção social. O gênero é entendido por ela como um aparato dessa construção social, uma produção discursiva, cujo efeito é a naturalização do sexo e sua estrutura binária. Isso significa que o corpo não é sexuado em nenhum sentido significativo, não pode ser dito masculino ou feminino antes de sua determinação em um discurso que o investe de uma ideia de sexo natural, no contexto das relações de poder.

Essa construção social do sistema de sexo e gênero é performática, segundo a autora, porque ele é criado e mantido em uma estrutura binária por meio da repetição reiterada de atos ou performances do feminino e do masculino. E, de tanto serem repetidas, as performances são percebidas como fatos naturais, ahistóricos. Assim, masculinidade ou feminilidade verdadeiras ou permanentes não existem, só são percebidas como tal de tanto que foram e são repetidas no nosso cotidiano, por todos nós.

O trabalho de desconstrução realizado pela teoria queer incide também sobre a ideia de heterossexualidade como predisposição natural e prática sexual comum a todos os indivíduos. Butler (1990/2013) argumenta que, do mesmo modo como acontece com a divisão binária dos sexos, a heterossexualidade não é uma predisposição sexual prédiscursiva, primária, anterior a seu surgimento enquanto norma. Ser sexuado implica, portanto, estar submetido a um conjunto de regulações sociais, que cria correlações necessárias entre sexo, gênero, prazeres e desejo.

A contrapartida política do trabalho de desconstrução social é a forte denúncia dos efeitos dessa norma binária e heterossexual sobre as subjetividades, seus corpos e sexualidades. Da produção de linhas causais de ligação entre sexo biológico, identidade de gênero e desejo sexual, resulta uma divisão entre identidades de gênero legítimas e ilegítimas. As legítimas são as que demonstram "coerência" nessa sequência produzida: corpos femininos que se identificam como mulheres e desejam homens ou corpos masculinos que se identificam como homens e desejam mulheres. 
Já as identidades de gênero ilegítimas são as que rompem com essa linha causal, que não se conformam às normas de inteligibilidade cultural. São, por isso, consideradas desviantes, abjetas, e sofrem exclusão e violência. É o que acontece com a homossexualidade e, mais radicalmente, com a transexualidade, que pode revelar uma descontinuidade absoluta entre sexo, gênero e desejo.

Vale afirmar, mais uma vez, que essas identidades legítimas e ilegítimas são efeitos de poder. A norma produz tanto a heterossexualidade e a cisgeneridade sancionadas, autorizadas, quanto a homossexualidade e a transexualidade negadas, excluídas. Há um ideal normativo de um sexo já portador de um gênero específico, que unifica funções, significados corporais, processos psicológicos e somáticos sem correlação necessária uns com os outros. Ideal que diz ainda quais são as regiões do corpo passíveis de proporcionarem prazer, denominando de partes sexuais o pênis, a vagina, os seios, e assim por diante, e restringindo o corpo erógeno a elas.

A heterossexualização do desejo requer e institui a produção de oposições discriminadas e assimétricas entre "feminino" e "masculino", em que estes são compreendidos como atributos expressivos de "macho" e "fêmea". A matriz cultural por intermédio da qual a identidade de gênero se torna inteligível exige que certos tipos de "identidade" não possam "existir" - isto é, aquelas em que o gênero não decorre do sexo e aquelas em que as práticas do desejo não "decorrem" nem do “sexo" nem do "gênero". (Butler, 1990/2013, pp. 38-39)

Concordando com Butler, Paul B. Preciado (2002) define o sexo, enquanto órgão e prática, como uma tecnologia de dominação heterossexual, que reduz o corpo a zonas erógenas em função de uma distribuição assimétrica do poder entre os gêneros. Sua ideia, portanto, é a de que os órgãos sexuais como tais são o produto de uma tecnologia sofisticada que prescreve que eles adquirem significação nas relações sexuais e que devem ser utilizados de acordo com sua "natureza", isto é, em relações heterossexuais.

O sistema de sexo-gênero é um sistema de escritura. O corpo é um texto socialmente construído, um arquivo orgânico da história da humanidade como história da produção-reprodução sexual, na qual certos códigos se naturalizam, outros ficam elípticos e outros são sistematicamente eliminados ou tachados. A (hetero)sexualidade, longe de surgir espontaneamente de cada corpo recém-nascido, 
deve re-inscrever-se ou re-instituir-se através de operações constantes de repetição e de re-citação dos códigos (masculino e feminino) socialmente investidos como naturais. (Preciado, 2002, pp. 23, tradução minha)

Também os papeis e práticas sexuais que são naturalmente atribuídos aos gêneros feminino e masculino são um conjunto arbitrário de regulações inscritos nos corpos. Inversamente, a exclusão de determinadas relações entre sexos e gêneros, assim como a designação de certas zonas do corpo como não-sexuais, são o resultado de operações que naturalizam as práticas que conhecemos como sexuais.

Recorrendo ao termo "pos-op", abreviação de Post operatório que designa no vocabulário médico a pessoa transexual que passou pela cirurgia de mudança de sexo, Preciado (2002) diz que somos todos "pos-op", na medida em que já fomos operados por tecnologias sociais. Isto é, tanto as pessoas trans que passaram por vaginoplastia ou faloplastia quanto as cis que não se submeteram a cirurgias têm em comum corpos produzidos, moldados pela norma heterossexual e binária. Não há corpos livres para a transexualização, portanto: “O conjunto destes processos de 'reatribuição' é o segundo recorte, a segunda fragmentação do corpo. Esta não é mais violenta que a primeira, é simplesmente mais gore [sangrenta], e sobretudo mais cara" (Preciado, 2002, p. 104, tradução minha). Além de denunciar os efeitos da norma de produção de um campo de subjetividades marginalizadas, indizíveis, ininteligíveis, a teoria queer vai adiante: pensa a resistência e a subversão da norma a partir justamente desse lugar marginalizado. Ou seja, valoriza e inclusive dá importância política aos fracassos diante da norma, às reconfigurações e reposicionamentos diante dela.

Butler (1990/2013) chama essas resistências e subversões no campo da sexualidade e do gênero de "paródias de gênero", e as entende também como repetições de performances, mas com a particularidade de serem performances disruptivas, perturbadoras, contestadoras. Isto é, elas se apoiam e se apropriam de categorias existentes e produzem algo diferente, que denuncia fracassos e incoerências das normas tidas como verdadeiras e ahistóricas.

Um exemplo de paródia de gênero dado por Butler (1990/2013) é a drag queen. Dressed as a girl, a expressão é usada para definir homens que se vestem com roupas e acessórios associados ao gênero feminino, produzindo um visual exageradamente feminino. Ao trazer uma imitação exagerada do que é tido socialmente como feminilidade, a performance de gênero da drag denuncia que também essa feminilidade entendida como "original" é uma imitação artificial, tão repetida por tanta gente que parece natural. Desse 
modo, no que diz respeito às transexualidades, a teoria queer, em primeiro lugar, denuncia o fato de elas, por não corresponderem às normas binárias de sexo e gênero, às identidades de gênero tidas como legítimas, serem consideradas desviantes, abjetas, e assim excluídas do campo de inteligibilidade social, ficando vulneráveis a uma série de violências, físicas e simbólicas. Em segundo lugar, aposta justamente nessa ruptura com as normas que as transexualidades realizam, a considerando uma força política importante, de transgredir e perturbar esse sistema normativo binário que não é estruturante da cultura, e sim construído. $\mathrm{Ou}$ seja, os teóricos queer positivam as experiências trans em seus trânsitos e embaralhamentos de fronteiras, em suas reapropriações da feminilidade e da masculinidade. Preciado (2002) defende inclusive que as intervenções corporais e cirurgias feitas pelos transexuais não deveriam servir para a re(adequação) dos corpos a uma suposta coerência masculina ou feminina, e sim para o embaralhamento e a confusão dos gêneros. E é justamente um experimento para confundir os gêneros que ele fez no próprio corpo e descreve em Testo Junkie: sexo, drogas e biopolítica na era farmacopornográfica (2018): se autoaplicou testosterona durante 236 dias, não para se tornar um homem, mas para experimentar o caráter tecnoconstruído, múltiplo e mutável do corpo e seus prazeres, e produzir uma nova plataforma sexual e afetiva, nem masculina nem feminina.

É uma questão de devires, de se tornar, de multiplicidades. (...) Não se trata de passar de mulher para homem ou de homem para mulher, mas de contaminar as bases moleculares da produção da diferença sexual, entendendo que estes dois estados do ser, homem e mulher, existem apenas como ficções políticas, como efeitos somáticos dos processos técnicos de normatização. (Preciado, 2018, p. 153)

A teoria queer, portanto, em vez de tipificar as transexualidades e reduzi-las a uma única categoria ou posição subjetiva, valoriza justamente sua potência para perturbar o sistema de sexo e gênero instituído e construir novos sentidos para o masculino e o feminino. Em suas variadas experiências, as pessoas transexuais evidenciam que as verdades tidas como universais não se aplicam a elas. Abrem, dessa maneira, espaço para a construção de novos dispositivos, novas políticas de verdade menos excludentes e que positivem as diferenças. 


\section{Clínica e novas subjetivações}

Dessa maneira, a teoria queer nos fornece pistas bastante interessantes na direção de novos olhares para as transexualidades. Ao retirar as pessoas trans do lugar do desviante e do patológico, valorizando suas experiências de trânsito, aponta também para a possibilidade de outra escuta clínica: que não reforce modelos de inteligibilidade, diagnósticos ou direções de tratamento já dados, e sim que tenha como norte a escuta de cada sujeito e seu desejo, aceitando que as possibilidades de subjetivação não são conhecidas a priori nem pelo analisando nem pelo analista.

No artigo "A psicanálise e o perigo trans (ou: por que psicanalistas têm medo de travestis?)", Cunha (2016) traz a hipótese de que o apego de psicanalistas a modelos de inteligibilidade que já preveem posições subjetivas passíveis de serem ocupadas se deve à sua resistência à indeterminação das sexualidades: "estaremos nós, psicanalistas, prontos a suportar tal indeterminação, sem o apoio de normas hierarquizantes que a regulem no plano das singularidades contingentes?" (p. 16). Sugere que, em vez de nos defendermos da força das pulsões, aceitemos que tudo é possível nos encontros dos corpos e também na clínica. Arán (2006), Ayouch $(2015)$ e Porchat $(2014,2018)$ também privilegiam, como vimos, a singularidade das experiências trans e a ideia de que não há roteiros fechados na clínica.

Hormonização ou cirurgias, cada um faz uma escolha, vai até um certo ponto e isso não o torna menos ou mais trans, transexual, transgênero, travesti, ou, enfim, o nome que essa pessoa queira usar para falar de si, de sua identidade. Essa é justamente a ideia de uma hipersingularidade que, por sua vez, combina um dos sentidos atribuídos ao queer. (Porchat, 2018, pp. 80)

Esses autores também nos chamam a atenção para a importância de levarmos em consideração na clínica que o sofrimento experimentado por pacientes transexuais também está relacionado à produção de inteligibilidade, abjeção e vulnerabilidade social pelo sistema de sexo e gênero hegemônico, denunciado pelos teóricos queer. Ou seja, é necessário estarmos atentos ao contexto social no qual a transexualidade se insere. Ayouch (2015) dá o nome de psicanálise da pós-transexualidade a essa psicanálise tanto subjetiva quanto social, que 
almejaria situar o sujeito no enquadre social, histórico e político no qual ele se inscreve, e abordar o inconsciente a partir do sistema sexo/gênero. Essa psicanálise visaria analisar o funcionamento das prescrições de gênero na subjetivação, nas relações do sujeito com os outros, mas também na sua própria perspectiva, como teoria que não escapa às formações discursivas dentro das quais ela surge. (Ayouch, 2015, pp. 26)

Essa psicanálise é chamada por ele de psicanálise da pós-transexualidade porque deve se desfazer da noção de transexualidade inventada pela psiquiatria e que está vinculada à diferença sexual binária, suposta ahistórica. Ou seja, a proposta de Ayouch (2015) é que a psicanálise se "despsiquiatrize", questione o seu próprio uso da categoria de diferença entre os sexos de modo a se abrir à multiplicidade e à subversão das características do gênero.

\section{Considerações Finais}

"O que assusta é perceber que tão pouco saber, dito científico, gerou tanto poder" (Bento, 2012, p. 93). Essa é a frase com que Berenice Bento encerra um dos capítulos de seu livro sobre o que é transexualidade, e a escolhi para concluirmos aqui também porque acredito que ela traduz as complexas relações entre saber e poder que perpassam os discursos sobre as transexualidades na atualidade.

O que esse artigo pretendeu fazer, em primeiro lugar, foi apresentar e problematizar os efeitos de poder próprios a certos discursos, produzidos no campo da medicina e da psicanálise. Em segundo, a partir do questionamento das prerrogativas e fundamentos desses discursos, e do recurso à teoria queer e à psicanálise, defender a possibilidade de se constituir uma nova política de verdade sobre as transexualidades, e, desse modo, uma escuta clínica mais aberta ao singular e ao novo.

Foucault (1979/2007) diz que a tarefa política do intelectual é ativar saberes não legitimados, desqualificados, contra os efeitos de poder e de produção de subjetividade de discursos teóricos unitários, que se pretendem científicos e verdadeiros. Novas teorias, ideias e reflexões são possíveis e necessários hoje, e podem fornecer novas pistas para a clínica. É nessa direção que este artigo quis apontar. No que diz respeito à clínica, a aposta é na possibilidade de termos uma escuta que não reforce a norma de sexo e de gênero (binária, heterossexual) vigente em nossa cultura, que recorra a outros conceitos, outros dispositivos 
que reguem a sexuação, menos excludentes e violentos, que respeitem mais as diferenças e as singularidades.

\section{Referências}

Arán, M. (2006). A transexualidade e a gramática normativa do sistema sexo-gênero. Ágora: Estudos em Teoria Psicanalítica, 9(1), 49-63. doi:10.1590/S151614982006000100004

Ayouch, T. (2015). Da transexualidade às transidentidades: Psicanálise e gêneros plurais. Percurso, 28(1), 23-32. Recuperado de https://hal.archives-ouvertes.fr/hal-01498414

Bento, B. (2012). O que é transexualidade. São Paulo, SP: Brasiliense.

Butler, J. (2004). Deshacer el género. Barcelona: Paidós.

Butler, J. (2013). Problemas de gênero: Feminismo e subversão de identidade. Rio de Janeiro, RJ: Civilização Brasileira. (Obra original publicada em 1990).

Butler, J. (2017). A vida psíquica do poder: Teorias da sujeição. Belo Horizonte, MG: Autêntica. (Obra original publicada em 1997).

Castel, P. -H. (2003). Le metámorphose impensable: Essai sur le transsexualisme et l'identité personnelle. Paris: Gallimard.

Chiland, C. (2008). O transexualismo. São Paulo, SP: Edições Loyola.

Cunha, E. L. (2016). A psicanálise e o perigo trans (ou: Por que psicanalistas têm medo de travestis?). Revista Periódicus, 5(1), 7-22. doi:10.9771/peri.v1i5.17172

Czermak, M. (1982). Précisions sur la clinique du transsexualisme. Le discours psychanalytique, 3(1), 16-22.

Foucault, M. (1969). A arqueologia do saber. Rio de Janeiro, RJ: Forense Universitária.

Foucault, M. (1983) The Subject and Power. In: H. Dreyfus, P. Rabinow (Orgs.), Michel Foucault: Beyond Structuralism and Hermeneutics (pp. 208-226). Chicago: University Of Chicago Press.

Foucault, M. (2007). Microfísica do poder (24a ed.). Rio de Janeiro, RJ: Graal. (Obra original publicada em 1979).

Frignet, H. (2002). O transexualismo. Rio de Janeiro, RJ: Companhia de Freud.

Jorge, M. A., \& Travassos, N. (2017). A epidemia transexual: histeria na era da ciência e da globalização?. Revista Latinoamericana de Psicopatologia Fundamental, 20(2), 307330. doi:10.1590/1415-4714.2017v20n2p307.7 
Lacan, J. (1995). O seminário - livro 3: As psicoses. Rio de Janeiro, RJ: Zahar. (Obra original publicada em 1956)

Lacan. J. (2009). O seminário - livro 18: De um discurso que não fosse semblante. Rio de Janeiro, RJ: Zahar. (Obra original publicada em 1971).

Melman, C. (1996). Le corps est-il le lieu de La vérité? In: M. Czermak, \& H. Frignet (Orgs.), Sur l'identité sexuelle: à propos du transsexualisme (pp. 397-409). Paris: Association freudienne internationale.

Millot, C. (1992). Extrasexo: ensaio sobre o transexualismo. São Paulo, SP: Escuta.

Pombo, M. (2019). Estrutura ou dispositivo: Como (re)pensar a diferença sexual hoje?. Revista Estudos Feministas, 27(2), 1-11. doi:10.1590/1806-9584-2019v27n254194

Porchat, P. (2010). Conversando sobre psicanálise: Entrevista com Judith Butler. Revista Estudos Feministas, 18(1), 161-170. doi:10.1590/S0104-026X2010000100009

Porchat, P. (2014). A transexualidade hoje: Questões para pensar o corpo e o gênero na psicanálise. Revista Brasileira de Psicanálise, 48(4), 115-126. Recuperado de https://repositorio.unesp.br/handle/11449/125095?show=full

Porchat, P. (2018). (In)diferenças sociais, (In)diferenças de gênero: O olhar da psicanálise para as masculinidades trans. SIG: Revista de Psicanálise, 7(1), 79-88. Recuperado de http://sig.org.br/wp-content/uploads/2019/09/Edicao12-Convidado2.pdf

Preciado, B. (2002). Manifiesto contra-sexual. Madrid: Opera Prima.

Preciado, B. (2018). Testo Junkie: Sexo, drogas e biopolítica na era farmacopornográfica. São Paulo: n-1 edições.

Roudinesco, E., \& Plon, M. (1998). Dictionnaire de la Psychanalyse. Paris: Fayard.

Stoller, R. (1968). Sex and gender: On the development of masculinity and femininity. New York: Science House.

Stoller, R. (1982). A experiência transexual. Rio de Janeiro, RJ: Imago. (Obra original publicada em 1975).

Endereço para correspondência

\section{Mariana Pombo}

Departamento de Psicologia - Instituto de Educação da UFRRJ

BR 465, KM 07, Seropédica - RJ, Brasil. CEP 23890-000

Endereço eletrônico: marifpombo@gmail.com 
Recebido em: 01/07/2019

Reformulado em: 01/06/2020

Aceito em: 05/06/2020

\section{Notas}

* Psicanalista e professora adjunta do Departamento de Psicologia da UFRRJ. Doutora e pós-doutora em Teoria Psicanalítica pelo PPGTP/UFRJ.

${ }^{1} \mathrm{Na}$ teoria lacaniana do Complexo de Édipo, a criança precisa, para se separar da mãe, de um apoio exterior, uma lei, que vem do pai simbólico. Nome-do-Pai é então o significante que introduz a lei da interdição do incesto no inconsciente enquanto lei simbólica. Já a foraclusão do Nome-do-pai refere-se a um mecanismo específico da psicose, por meio do qual o significante Nome-do-Pai é rejeitado, abolido. Ou seja, não é integrado ao inconsciente, como acontece no recalque, mecanismo típico da neurose, e retorna no real sob a forma de uma alucinação ou um delírio que invadem a fala ou a percepção do sujeito (Lacan, 1956/1995; Roudinesco \& Plon, 1998).

${ }^{2}$ Para uma problematização do conceito de diferença sexual na contemporaneidade e uma interrogação da ahistoricidade e imutabilidade dessa categoria, ver: Pombo, M. (2019). Estrutura ou dispositivo: como (re)pensar a diferença sexual hoje?. Revista Estudos Feministas, 27(2), p. 1-11.

Financiamento: FAPERJ (Bolsa de Pós-Doutorado Nota 10).

Este artigo de revista Estudos e Pesquisas em Psicologia é licenciado sob uma Licença Creative Commons Atribuição-Não Comercial 3.0 Não Adaptada. 